\title{
Perfusion-based human cadaveric specimen as a simulation training model in repairing cerebrospinal fluid leaks during endoscopic endonasal skull base surgery
}

\author{
Eisha A. Christian, MD, ${ }^{1}$ Joshua Bakhsheshian, MD, ${ }^{1}$ Ben A. Strickland, MD, ${ }^{1}$ \\ Vance L. Fredrickson, MD, ${ }^{1}$ lan A. Buchanan, MD, ${ }^{1}$ Martin H. Pham, MD, ${ }^{1}$ Andrew Cervantes, BS, ${ }^{2}$ \\ Michael Minneti, BS, ${ }^{2}$ Bozena B. Wrobel, MD, ${ }^{3}$ Steven Giannotta, MD, ${ }^{1}$ and Gabriel Zada, MD ${ }^{1}$ \\ Departments of ${ }^{1}$ Neurological Surgery and ${ }^{3}$ Otolaryngology, Keck School of Medicine; and ${ }^{2}$ Surgical Skills and Simulation Center, \\ Department of Surgery, University of Southern California, Los Angeles, California
}

\begin{abstract}
OBJECTIVE Competency in endoscopic endonasal approaches (EEAs) to repair high-flow cerebrospinal fluid (CSF) leaks is an essential component of the neurosurgical training process. The objective of this study was to demonstrate the feasibility of a simulation model for EEA repair of anterior skull base CSF leaks.

METHODS Human cadaveric specimens were utilized with a perfusion system to simulate a high-flow CSF leak. Neurological surgery residents (postgraduate year 3 or greater) performed a standard EEA to repair a CSF leak using a combination of fat, fascia lata, and pedicled nasoseptal flaps. A standardized 5-point Likert questionnaire was used to assess the knowledge gained, techniques learned, degree of safety, benefit of CSF perfusion during repair, and pre- and postraining confidence scores.
\end{abstract}

RESULTS Intrathecal perfusion of fluorescein-infused saline into the ventricular/subarachnoid space was successful in 9 of 9 cases. The addition of CSF reconstitution offered the residents visual feedback for confirmation of intraoperative CSF leak repair. Residents gained new knowledge and a realistic simulation experience by rehearsing the psychomotor skills and techniques required to repair a CSF leak with fat and fascial grafts, as well as to prepare and rotate vascularized nasoseptal flaps. All trainees reported feeling safer with the procedure in a clinical setting and higher average posttraining confidence scores (pretraining $2.22 \pm 0.83$, posttraining $4.22 \pm 0.44, p<0.001$ ).

CONCLUSIONS Perfusion-based human cadaveric models can be utilized as a simulation training model for repairing CSF leaks during EEA.

https://thejns.org/doi/abs/10.3171/2017.5.JNS162982

KEY WORDS endoscopic skull base surgery; cerebrospinal fluid leak repair; resident training; surgical simulation

$\mathrm{T}$ HE development of proficient technical surgical skills and clinical decision making is requisite to achieving competency in skull base surgery during residency training. Endoscopic endonasal approaches (EEAs) to the skull base carry a unique set of technical challenges that must be overcome and require certain psychomotor skills that must be gained while progressing along the learning curve. Particular challenges in EEA often include working with reduced depth perception and a lack of stereoscopic vision, operating via minimal-access corridors, interacting with an additional surgeon driving the endoscope, avoiding collisions between the endoscope and instruments, and managing difficulties with general visualization. Cerebrospinal fluid (CSF) leaks are among the most common complications associated with direct and extended endoscopic endonasal skull base approaches. ${ }^{18,19}$ As EEAs to skull base surgery continue to evolve, achieving competency in the repair of high-flow CSF leaks will become an essential component of the training process. Numerous techniques and adjuncts for CSF leak repair are currently available and include intrathecal fluorescein,,$^{15}$ autologous or synthetic graft apposition, gasket

ABBREVIATIONS CSF = cerebrospinal fluid; EEA = endoscopic endonasal approach; LAC = Los Angeles County; PGY = postgraduate year; USC = University of Southern California.

SUBMITTED November 29, 2016. ACCEPTED May 11, 2017.

INCLUDE WHEN CITING Published online November 3, 2017; DOI: 10.3171/2017.5.JNS162982. 


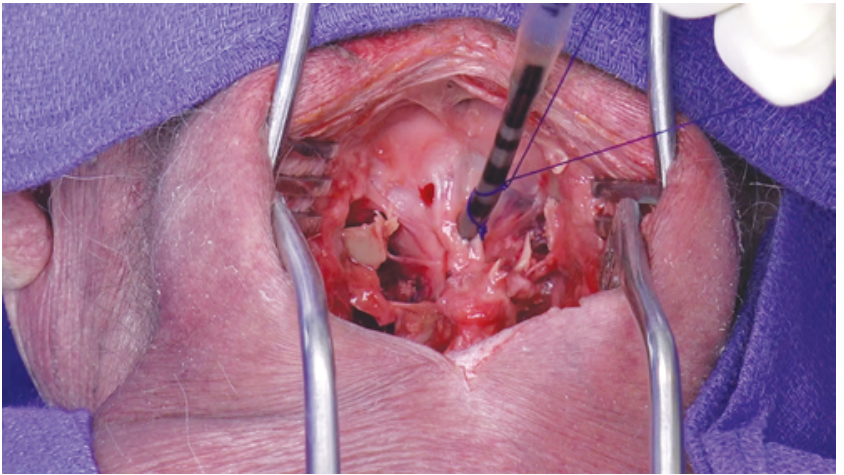

FIG. 1. Intrathecal insertion of a pediatric extracorporeal membrane oxygenation (ECMO) cannula after cervical laminectomy and durotomy. Figure is available in color online only.

seal techniques with rigid buttressing, and a vascularized nasoseptal flap. ${ }^{5,9,10,13}$

In the current era of resident work-hour restrictions and medical liability concerns, there has been significant interest in modifying the surgical education paradigm with simulation-based training. ${ }^{11}$ The use of simulated surgical models allows trainees to hone their technical skills in a safe environment and enhance their operative skill sets. ${ }^{3,6}$ The objective of this study was to report on the feasibility of a simulation model for endoscopic endonasal repair of skull base CSF leaks using intrathecal fluorescein for identification and various techniques for repair.

\section{Methods}

\section{Setting and Cadavers}

All cadaveric dissections in this feasibility pilot study were performed at the Keck School of Medicine of USC Fresh Tissue Dissection Laboratory, based at the Los Angeles County + University of Southern California (LAC+USC) Medical Center. This laboratory has access to fresh unfixed cadavers available through an unclaimed deceased program sanctioned by the LAC+USC Medical Center, USC Department of Pathology, and LAC Coroner. The setting is intended to mimic an operating room. The mock operating theater is equipped with an endoscopy system (Karl Storz Inc.) along with a high-speed drill, irrigation, and a variety of microdissection instruments tailored for endoscopic endonasal procedures.

\section{Perfusion Model}

A perfusion pump was used to intrathecally perfuse fluorescein-dyed saline (CSF substitute) into human cadavers after a cervical laminectomy and durotomy had been performed for access. Five fresh unfixed cadaveric bodies were used for this study. The initial step in cadaveric preparation was a 1-level cervical laminectomy and durotomy after which a pediatric cannula was inserted into the subdural intrathecal space and secured to the soft tissue (Fig. 1). Dura, fascia, and skin were then closed in a watertight manner, and the specimen was turned supine. A standard EEA to the sellar region was performed with preparation of a vascularized nasoseptal flap described as

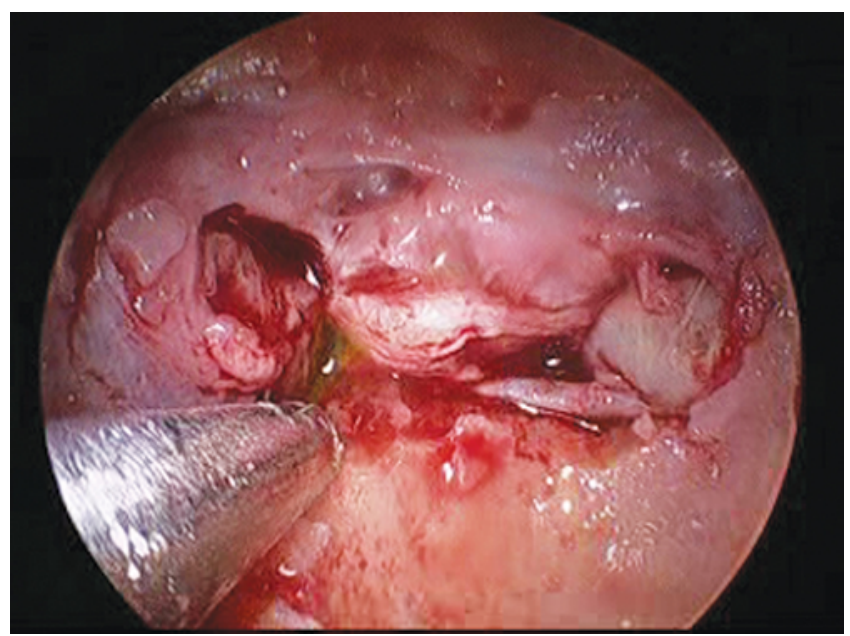

FIG. 2. Suprasellar CSF leak. Figure is available in color online only.

the Hadad-Bassagasteguy flap by Hadad et al. ${ }^{9}$ and popularized by Kassam et al. ${ }^{10} \mathrm{~A}$ perfusion pump was used to intrathecally infuse fluorescein-dyed saline to reconstitute the ventricular and subarachnoid spaces $(0.1 \mathrm{ml}$ of fluorescein per $10 \mathrm{ml}$ of preservative-free saline), strictly to offer improved visualization of persistent CSF leakage following repair and to enhance the quality of figures and videos rather than to identify a CSF leak location. The CSF reconstitution system was connected to the Medtronic Bio-Pump (BP-80), and the initial continuous saline flow had a pressure of $15 \mathrm{~mm} \mathrm{Hg}$. After initiation of the intrathecal perfusion, a CSF leak was deliberately created in the suprasellar arachnoid (Fig. 2). Trainees then practiced repairing the CSF leak using a combination of fat, fascia lata, and pedicled nasoseptal flaps (Fig. 3). Standard CSF repair techniques included a 2-layer fascial apposition method, as described by Couldwell et al., in which the sella turcica was packed with a fat graft and covered using a pedicled nasoseptal flap (Video 1). ${ }^{5}$

VIDEO 1. Video demonstrating the use of a perfusion-based human cadaveric specimen as a simulation training model in repairing CSF leaks during endoscopic endonasal skull base surgery. The video captures the simulation during identification of the ostium, elevation of a nasoseptal flap, exposure of the sella, dural opening, identification of CSF leak simulation with fluorescein, and finally the repair process. Copyright Joshua Bakhsheshian. Published with permission. Click here to view.

The pressure of the CSF perfusion was increased up to 40 $\mathrm{mm} \mathrm{Hg}$ to simulate a Valsalva maneuver to help evaluate persistent leakage.

\section{Statistical Analysis}

A 5 -point Likert scale $(1=$ no confidence, $5=$ high confidence) was used to assess pre- and posttraining confidence. Descriptive statistics were available on each resident's evaluation ( 1 = strongly disagree, $3=$ neutral, $5=$ strongly agree) in terms of gaining new knowledge, learning new techniques, feeling safer performing the procedure, and having a more realistic experience with the addition of perfusion. Data from neurological surgery residents in postgraduate year (PGY)-3 or later were ana- 

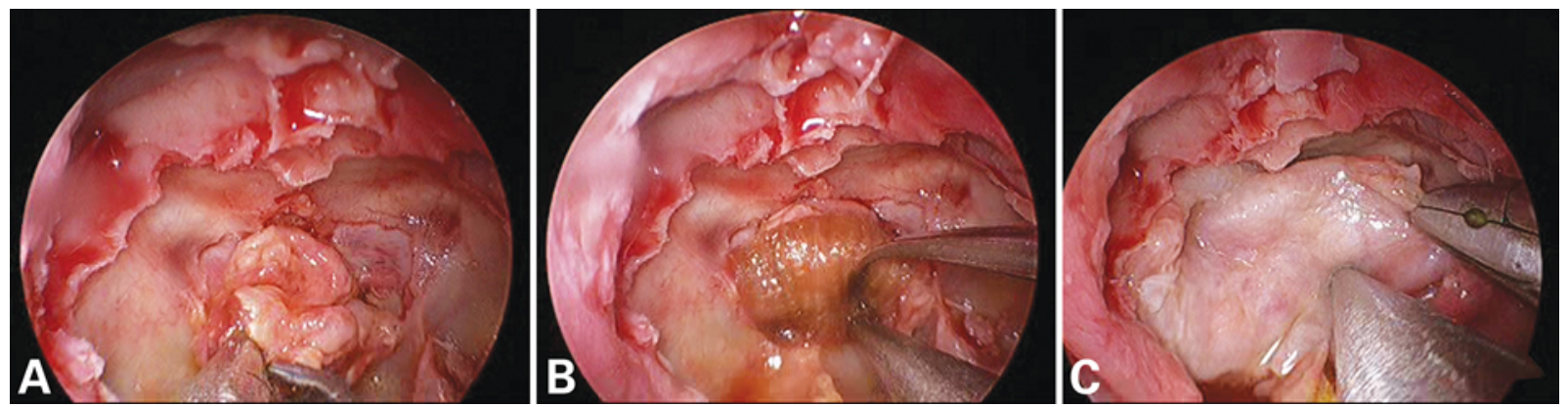

FIG. 3. Repair of CSF leak: Step 1, fascia lata (A); Step 2, Surgicel (B); Step 3, nasoseptal flap (C). Figure is available in color online only.

lyzed. Statistical significance between pre- and posttraining confidence scores was evaluated with the Student t-test (unpaired, 2-tailed, $\alpha=0.05$ ) using Microsoft Excel.

\section{Results}

Nine resident trainees from neurological surgery participated in this study and ranged from PGY-3 to PGY6 (Table 1). Intrathecal perfusion of saline into the ventricular and subarachnoid spaces was successful in all 9 cases. All trainees reported gaining new knowledge (4.67 $\pm 0.50)$, learning a new technique $(4.78 \pm 0.44)$, and feeling safer performing the procedure $(4.78 \pm 0.44)$. All trainees noted that the addition of CSF perfusion made it a more realistic model for intraoperative CSF leak repair (5.00 \pm $0.00)$. The average pretraining confidence was scored as $2.22 \pm 0.83$, and the average posttraining score was $4.22 \pm$ $0.44(\mathrm{p}<0.001)$.

The perfusion of saline with fluorescein was also successful in aiding identification of persistent CSF leaks following the initial repair process. Multiple trainees were able to use the CSF perfusion cadaveric model for CSF leak repair in the same setting. Five of the residents had the opportunity to be evaluated for proper identification of the ostium, lateralization of the middle turbinate, creation and securement of a pedicled nasoseptal flap, adequate exposure of the sellar floor, docking of the endoscope for an optimal midline endoscopic view, safe opening of the sellar floor, and dural opening while preventing collision between instruments.

\section{Discussion}

Endoscopic endonasal skull base surgery requires a separate skill set from that used in routine open and microscopic cranial procedures, and the learning curve can be quite steep for trainees attempting to master these procedures. In addition, these approaches are highly dependent on specific instrumentation and technology that are integral to successful completion of the operation. Simulators have been known to incorporate haptic feedback, which carries the potential of enhancing a trainee's sensory perception and facilitating the transfer of skills from the simulator to the operating room..$^{20}$ We have demonstrated the feasibility of using a perfusion-based human cadaveric specimen as a simulation training model in repairing CSF leaks during endoscopic endonasal anterior skull base surgery.

Multiple studies have shown improved outcomes and decreased complication rates in endoscopic endona-

TABLE 1. Questionnaire responses from 9 resident trainees on simulation training for CSF leak repair during endoscopic endonasal approaches

\begin{tabular}{|c|c|c|c|c|c|c|c|}
\hline Resident No. & $\begin{array}{l}\text { PGY } \\
\text { Level }\end{array}$ & $\begin{array}{l}\text { Gained New } \\
\text { Knowledge* }^{\text {Know }}\end{array}$ & $\begin{array}{l}\text { Learned New } \\
\text { Techniques* }\end{array}$ & $\begin{array}{l}\text { Felt Safer Performing } \\
\text { Procedure* }^{*}\end{array}$ & $\begin{array}{l}\text { Adding Perfusion } \\
\text { Increased Realism* }\end{array}$ & $\begin{array}{l}\text { Pretraining } \\
\text { Confidence† }\end{array}$ & $\begin{array}{l}\text { Posttraining } \\
\text { Confidence }\end{array}$ \\
\hline 1 & 6 & 4 & 4 & 4 & 5 & 3 & 5 \\
\hline 2 & 6 & 4 & 4 & 4 & 5 & 3 & 5 \\
\hline 3 & 5 & 5 & 5 & 5 & 5 & 3 & 4 \\
\hline 4 & 5 & 4 & 5 & 5 & 5 & 2 & 4 \\
\hline 5 & 4 & 5 & 5 & 5 & 5 & 3 & 4 \\
\hline 6 & 4 & 5 & 5 & 5 & 5 & 2 & 4 \\
\hline 7 & 3 & 5 & 5 & 5 & 5 & 2 & 4 \\
\hline 8 & 3 & 5 & 5 & 5 & 5 & 1 & 4 \\
\hline 9 & 3 & 5 & 5 & 5 & 5 & 1 & 4 \\
\hline Average score & & 4.67 & 4.78 & 4.78 & 5.00 & 2.22 & 4.22 \\
\hline
\end{tabular}

* Rating scale: 1 = strongly disagree; 3 = neutral; 5 = strongly agree.

$\dagger$ Based on a 5-point Likert scale: $1=$ no confidence; $5=$ high confidence. 
sal techniques with increasing trainee experience. ${ }^{4,12,14}$ O'Malley et al. demonstrated in a retrospective review of 25 patients that the surgical time for endoscopic pituitary surgery decreased by 1 hour as surgeons became more familiar with the procedure, with a trend toward decreased rates of CSF leaks and other complications. ${ }^{14}$ Koutourousiou et al. demonstrated that the learning curve had significant impact on gross-total resections of cranial base chordomas via the EEA. ${ }^{12}$ They observed an improvement in gross-total resection rates from $36.4 \%$ to $88.9 \%$ when they retrospectively studied 60 patients over 8 years. ${ }^{12}$

Achieving competency in the repair of high-flow CSF leaks with various skull base reconstructive techniques is an essential component of the training process in skull base surgery. One of the inherent risks in endonasal skull base surgery is the development of a postoperative CSF leak, which places the patient at risk for pneumocephalus and meningitis. Prior to the advent of the vascularized nasoseptal flap, postoperative CSF leak rates were reported as $20 \%-30 \%$ of extended endoscopic endonasal cases. ${ }^{24}$ In a retrospective analysis of endoscopic skull base repair in 151 patients, Thorp et al. demonstrated that the use of vascularized flaps can result in a postoperative CSF leak rate of 3.3\%. ${ }^{21}$ Given the improvement in complication rates with the new flap-based surgical techniques, it is important for residents to obtain the adequate training and competency to learn this skill set for repairing skull base CSF leaks. This can be achieved through participating in a realistic simulation environment rather than relying solely on intraoperative exposure.

Perfusion-based human cadaveric specimens have been used in surgical training with great potential in aiding the development of skill sets necessary for specialized surgical procedures. ${ }^{1,2,7,8,17,22,23,25}$ Although virtual reality applications for EEAs are available, ${ }^{16}$ they are unable to replicate the tissue quality required for adequate training in CSF leak repair. Our model provides a realistic training setup for neurosurgical residents to repair CSF leaks using fresh tissue (fat grafts, fascial grafts, and so forth) and the potential to practice elevating and positioning vascularized nasoseptal flaps. A pulsatile pressure pump system was not used to emulate pulsatile CSF flow because of the complications associated with clamping and unclamping the system as needed between each trial. The addition of fluorescein offered the opportunity to further evaluate novel intraoperative protocols for identification and confirmation of adequate repair of intraoperative CSF leaks. However, this investigation was not designed to assess the added utility of fluorescein in CSF leak repairs or in identifying a site of initial CSF leakage, which is the common indication for intrathecal fluorescein use. Furthermore, our model can be expanded to include CSF leaks from the ethmoidal and other regions of the skull base.

The main limitation of our anatomical model is that fresh cadaveric specimens may not be readily available at all training centers because of the costs. Of note, the model does not require whole cadavers. Whole cadavers are used at our institution because they are supplied in that manner via the USC Fresh Tissue Laboratory. The setup could also be performed using cadaveric head or torso specimens and could be used in a repeated fashion for educational courses. Firm conclusions are limited by our study's small sample size and subjective questionnaires. It is noteworthy that all neurosurgical residents reported an increase in their confidence with this approach after utilizing the surgical simulation model. However, there is a need to identify objective performance measures specific to endoscopic endonasal anterior skull base surgery with long-term evaluations. Prospective validation of this model with respect to improvement in trainee psychomotor skills with repeated trials is needed and is currently being undertaken at our institution to objectively establish the validity and the value of this surgical simulation. The focus of this feasibility study was a preliminary evaluation on developing a realistic simulator for training residents in repairing CSF leaks during endoscopic endonasal anterior skull base surgery utilizing standard methods.

\section{Conclusions}

As endoscopic skull base surgery continues to evolve, achieving competency in repairing high-flow CSF leaks through various skull base reconstructive methods will be an increasingly essential component of the training process. The addition of an intrathecal perfusion system to a cadaveric simulation scenario can produce a realistic training model for developing the appropriate skill sets for various reconstructive methods in the endoscopic repair of CSF leaks.

\section{Acknowledgments}

We thank Rodrick A. Faccio for editorial assistance.

\section{References}

1. Aboud E, Aboud G, Al-Mefty O, Aboud T, Rammos S, Abolfotoh M, et al: "Live cadavers" for training in the management of intraoperative aneurysmal rupture. J Neurosurg 123:1339-1346, 2015

2. Aboud E, Al-Mefty O, Yaşargil MG: New laboratory model for neurosurgical training that simulates live surgery. J Neurosurg 97:1367-1372, 2002

3. Arriaga AF, Bader AM, Wong JM, Lipsitz SR, Berry WR, Ziewacz JE, et al: Simulation-based trial of surgical-crisis checklists. N Engl J Med 368:246-253, 2013

4. Cappabianca P, Cavallo LM, Colao A, de Divitiis E: Surgical complications associated with the endoscopic endonasal transsphenoidal approach for pituitary adenomas. J Neurosurg 97:293-298, 2002

5. Couldwell WT, Kan P, Weiss MH: Simple closure following transsphenoidal surgery. Technical note. Neurosurg Focus 20(3):E11, 2006

6. Dawe SR, Pena GN, Windsor JA, Broeders JA, Cregan PC, Hewett PJ, et al: Systematic review of skills transfer after surgical simulation-based training. Br J Surg 101:10631076, 2014

7. Garrett HE Jr: A human cadaveric circulation model. J Vasc Surg 33:1128-1130, 2001

8. Güvençer M, Sayhan S, Ay Dereli N, Tetik S, Yücesoy K, Arda MN: Simulation of cerebrovascular circulation in the human cadaver for surgical neuroanatomy training. Turk Neurosurg 17:243-246, 2007

9. Hadad G, Bassagasteguy L, Carrau RL, Mataza JC, Kassam A, Snyderman $\mathrm{CH}$, et al: A novel reconstructive technique after endoscopic expanded endonasal approaches: vascular pedicle nasoseptal flap. Laryngoscope 116:1882-1886, 2006 
10. Kassam AB, Thomas A, Carrau RL, Snyderman CH, Vescan A, Prevedello D, et al: Endoscopic reconstruction of the cranial base using a pedicled nasoseptal flap. Neurosurgery 63:ONS44-ONS53, 2008

11. Kirkman MA, Ahmed M, Albert AF, Wilson MH, Nandi D, Sevdalis N: The use of simulation in neurosurgical education and training. A systematic review. J Neurosurg 121:228246,2014

12. Koutourousiou M, Gardner PA, Tormenti MJ, Henry SL, Stefko ST, Kassam AB, et al: Endoscopic endonasal approach for resection of cranial base chordomas: outcomes and learning curve. Neurosurgery 71:614-625, 2012

13. Leng LZ, Brown S, Anand VK, Schwartz TH: "Gasket-seal" watertight closure in minimal-access endoscopic cranial base surgery. Neurosurgery 62 (5 Suppl 2):ONSE342-ONSE343, 2008

14. O'Malley BW Jr, Grady MS, Gabel BC, Cohen MA, Heuer GG, Pisapia J, et al: Comparison of endoscopic and microscopic removal of pituitary adenomas: single-surgeon experience and the learning curve. Neurosurg Focus 25:E10, 2008

15. Psaltis AJ, Schlosser RJ, Banks CA, Yawn J, Soler ZM: A systematic review of the endoscopic repair of cerebrospinal fluid leaks. Otolaryngol Head Neck Surg 147:196-203, 2012

16. Rosseau G, Bailes J, del Maestro R, Cabral A, Choudhury N, Comas O, et al: The development of a virtual simulator for training neurosurgeons to perform and perfect endoscopic endonasal transsphenoidal surgery. Neurosurgery 73 (Suppl 1):85-93, 2013

17. Russin JJ, Mack WJ, Carey JN, Minneti M, Giannotta SL: Simulation of a high-flow extracranial-intracranial bypass using a radial artery graft in a novel fresh tissue model. Neurosurgery 71 (2 Suppl Operative):ons315-ons320, 2012

18. Schlosser RJ, Bolger WE: Nasal cerebrospinal fluid leaks: critical review and surgical considerations. Laryngoscope 114:255-265, 2004

19. Strickland B, Lucas J, Harris B, Kulubya E, Bakhsheshian J, Liu C, et al: Identification and repair of intraoperative cerebrospinal fluid leaks in endonasal transphenoidal pituitary surgery: surgical experience in a series of 1002 patients. J Neurosurg [epub ahead of print September 29, 2017. DOI: 10.3171/2017.4.JNS162451]

20. Ström P, Hedman L, Särnå L, Kjellin A, Wredmark T, Felländer-Tsai L: Early exposure to haptic feedback enhances performance in surgical simulator training: a prospective randomized crossover study in surgical residents. Surg Endosc 20:1383-1388, 2006

21. Thorp BD, Sreenath SB, Ebert CS, Zanation AM: Endoscopic skull base reconstruction: a review and clinical case series of 152 vascularized flaps used for surgical skull base defects in the setting of intraoperative cerebrospinal fluid leak. Neurosurg Focus 37(4):E4, 2014
22. Tubbs RS, Loukas M, Shoja MM, Wellons JC, Cohen-Gadol AA: Feasibility of ventricular expansion postmortem: a novel laboratory model for neurosurgical training that simulates intraventricular endoscopic surgery. J Neurosurg 111:11651167, 2009

23. Winer JL, Kramer DR, Robison RA, Ohiorhenuan I, Minneti M, Giannotta S, et al: Cerebrospinal fluid reconstitution via a perfusion-based cadaveric model: feasibility study demonstrating surgical simulation of neuroendoscopic procedures. J Neurosurg 123:1316-1321, 2015

24. Zada G: Editorial. Vascularized flap reconstruction for CSF leaks during endoscopic skull base surgery. Neurosurg Focus 37(5):E5, 2014

25. Zada G, Bakhsheshian J, Pham M, Minneti M, Christian E, Winer J, et al: Development of a perfusion-based cadaveric simulation model integrated into neurosurgical training: feasibility based on reconstitution of vascular and cerebrospinal fluid systems. Oper Neurosurg (Hagerstown) [epub ahead of print], 2017

\section{Disclosures}

The authors report no conflict of interest concerning the materials or methods used in this study or the findings specified in this paper.

\section{Author Contributions}

Conception and design: Christian, Giannotta, Zada. Acquisition of data: Bakhsheshian, Christian, Minneti, Zada. Analysis and interpretation of data: Bakhsheshian, Christian, Wrobel, Zada. Drafting the article: Bakhsheshian, Christian. Critically revising the article: Bakhsheshian, Strickland, Fredrickson, Buchanan, Pham, Cervantes, Minneti, Wrobel, Giannotta, Zada. Reviewed submitted version of manuscript: all authors. Approved the final version of the manuscript on behalf of all authors: Bakhsheshian. Statistical analysis: Bakhsheshian. Administrative/technical/material support: Bakhsheshian, Strickland, Fredrickson, Buchanan, Pham, Cervantes, Minneti, Wrobel, Zada. Study supervision: Christian, Giannotta, Zada.

\section{Supplemental Information \\ Videos}

Video 1. https://vimeo.com/223160545.

\section{Correspondence}

Joshua Bakhsheshian, Department of Neurological Surgery, University of Southern California, Keck School of Medicine, 1200 North State St., Ste. 3300, Los Angeles, CA 90033. email: joshuabakh@gmail.com. 